\title{
Effects of GeoGebra towards students' mathematics performance
}

\begin{abstract}
The purpose of this study was to investigate the effects of using Dynamic Mathematics Software (GeoGebra) on students' performance compared to the regular instruction without using technology for a Geometry topic. A quasi-experimental post-test-only control group design was utilized in the study. The study involved 55 secondary school students (27 in the GeoGebra group, 28 in the control group) in a Malaysian school. Independent sample t-test analysis showed that students who were exposed to GeoGebra achieved significantly better test scores as compared to the group which followed the class without using any technology. However, the delayed post-test showed a different finding. The results from this study suggest that the integration of mathematical software in the teaching and learning of geometry is beneficial and the use of it should be continued.
\end{abstract}

Keyword: GeoGebra; Geometry; Open source software 